\title{
A Pilot Study for Case-Based Learning Among Undergraduate Students in Global Health
}

Raywat Deonandan Assistant Professor, Interdisciplinary School of Health Sciences, University of Ottawa Ottawa, Ontario Canada

Arif Jinha University of Ottawa Ottawa, Ontario Canada

Jason Benovoy University of Ottawa Ottawa, Ontario Canada

Michele Meilleur Sarazin University of Ottawa Ottawa, Ontario Canada

Jennifer Doswell University of Ottawa Ottawa, Ontario Canada

Citation: R. Deonandan, A. Jinha, J. Benovoy, M.M. Sarazin, J. Doswell : A Pilot Study for Case-Based Learning Among Undergraduate Students in Global Health. The Internet Journal of Medical Education. 2012 Volume 2 Number 2

Keywords: Global health CBL Education Undergraduate

\section{Abstract}

In this pilot study, students in a 4th year undergraduate course in Global Health at the University of Ottawa were exposed to Case-Based Learning $(C B L)$ for the first time; and their experiences were assessed via an online survey. Though the response rate was poor (21\%), respondents indicated overwhelmingly that the CBL experience was enjoyable, educational and appropriate for the subject. Aside from cost, the major challenge was harmonizing student experiences across the discussion groups, which may be addressed by better leader training. Given its innate opinion-based and interdisciplinary nature, Global Health is an appropriate subject area for the application of CBL to undergraduate teaching, and expansion of this intervention must include a wider selection of cases and greater harmonization of facilitation methods and leader training across groups.

\section{Introduction}

Since first pioneered at McMaster University four decades ago, problem-based learning (PBL) has spread to over 60 medical schools worldwide [1], and with it has come greater explorations of its close relative, case-based learning ( $\mathrm{CBL}$ ). The two educational techniques have proven sufficiently effective to spread to domains outside of Medical school, including classes in Engineering [2], Law [3] and a variety of undergraduate programs [4].

While its virtues are spreading across the sphere of pedagogy, the extent to which CBL can be applied to the undergraduate teaching of Global Health has not been explored in the literature. As a field of study, Global Health draws from the subjects of Epidemiology, Medicine, History, Economics and a number of other fields. It is therefore necessarily complex, and there are no standard methodologies or models for teaching it that are universally acknowledged. Global Health therefore does not lend itself to a purely didactic approach, since issues to be explored are typically nuanced by competing opinions, professional biases and political stances. Thus, approaching the teaching of Global Health from a case-based approach seems like an ideal tack.

At the University of Ottawa's bilingual (English/French) Interdisciplinary School of Health Sciences, the sole Global Health course is a very popular 4 th year offering, typically attracting 70-100 students per year. Several discussions have occurred at the faculty level regarding the possibility of employing more small group learning approaches, featuring a case-based approach, in a variety of classes. However, the major barrier to implementing CBL regularly is financial: the cost of case preparation, salaries of session leaders, and the cost of space allocation for conducting the sessions.

The one-day pilot study described herein was conducted to explore student reactions as a basis for a 
future expanded research project on using CBL for Global Health teaching. The intent of such an expanded study would be to inform an eventual administrative decision on whether to invest in regular CBL sessions for this and related classes.

\section{Methods}

As a pilot study, in the 2009-2010 school year, the 77 students of the 4 th year Global Health class of the bilingual Interdisciplinary School of Health Sciences at the University of Ottawa were given a mandatory one day CBL session, held on a weekend. Students were divided into six groups of 10-14 participants. Each group was led by a single individual, chosen from two professors, two graduate students and two high-performing undergraduate students. The two professors had previously received formal small group facilitation training by the Faculty of Medicine. The remaining leaders were given a brief overview of objectives and methodology.

The case was given to students a week in advance, and consisted of a discussion of the current (2010) famine in Northern Uganda. The objectives of the case were: (1) to understand some of the political and social barriers that impede the addressing of large scale famine; (2) to become aware of the health impacts and management challenges of famine and drought; (3) to become aware of some of the opposing arguments relating to the provision of food aid; and (4) to become aware of the increasing importance of globalization, cash crop economies, poor political management and Climate Change on large scale global health events, such as African famines.

Seven internet links were included to start students' search for more information relevant to the resulting discussion of the case. The discussion questions meant to help guide exploration of the issue are included in Appendix 1.

After the session, a voluntary online survey was sent to all students, hosted by SurveyMonkey.com. Ethics approval for this study was obtained from the University's research ethics office.

\section{Results}

There was a low response rate, with only 16 completed surveys (21\%), 15 of whom answered every question. All respondents were female (the class is $73 \%$ female), and none had ever experienced PBL or $\mathrm{CBL}$ before. One student was enrolled in the Nursing program, while all the others were registered in the undergraduate Health Sciences program. While the course is a 4 th year class, one respondent was in her $2 \mathrm{nd}$ year and three were in their $3 \mathrm{rd}$ year of their programs. And though the program is bilingual, 12 (75\%) of respondents claimed their mother tongue to be English. The remaining students individually reported Arabic, French, Urdu and Somali as their first languages.

Responses to the quantitative questions are summarised in Table 1, while a sample of the qualitative responses is given in Table 2. Key findings include that all respondents felt that the CBL session was either "moderately" or "quite" worthwhile. Eleven respondents (73\%) would have preferred to receive a lecture on the topic prior to endeavouring into CBL. And most importantly for the objectives of this study, 11 respondents $(73 \%)$ felt that $\mathrm{CBL}$ in small groups was a superior experience to a traditional lecture format. (Only one felt that there was no difference in preference between the two formats.) Additionally, 9 (60\%) reported that CBL was superior to a less structured, small group dynamic. A majority of 9 (64\%) would have liked to have had more CBL sessions in the year. They recommended the following topics: maternal care, health education in developing countries, and strategies for addressing epidemics. 


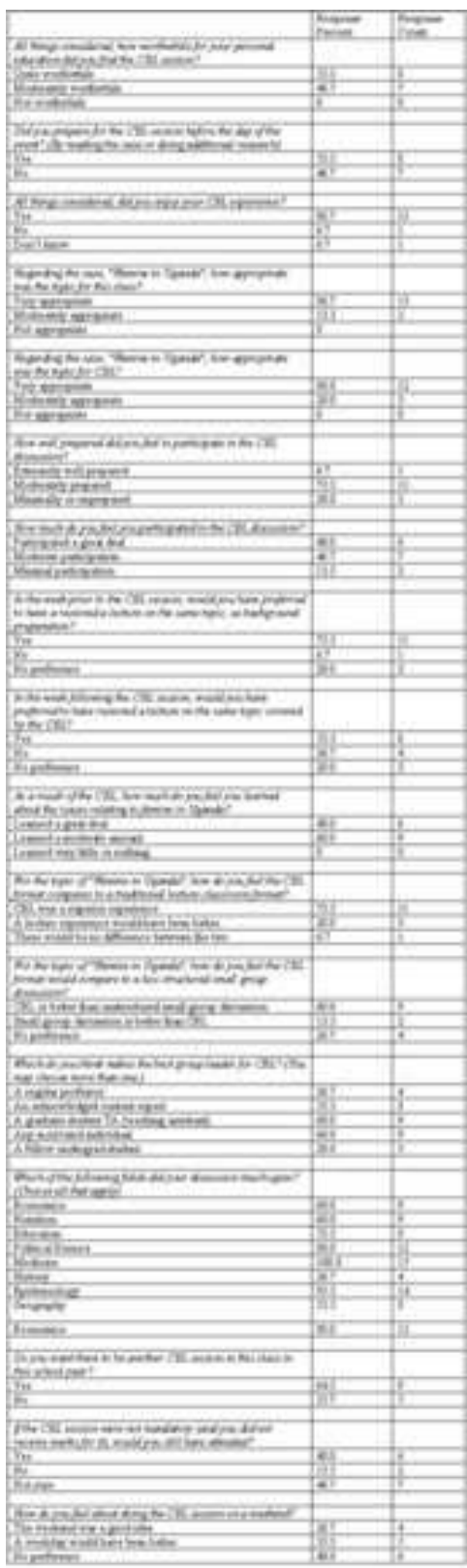

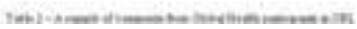

Table 1 - Summary of responses to the online survey on CBL for Global Health 


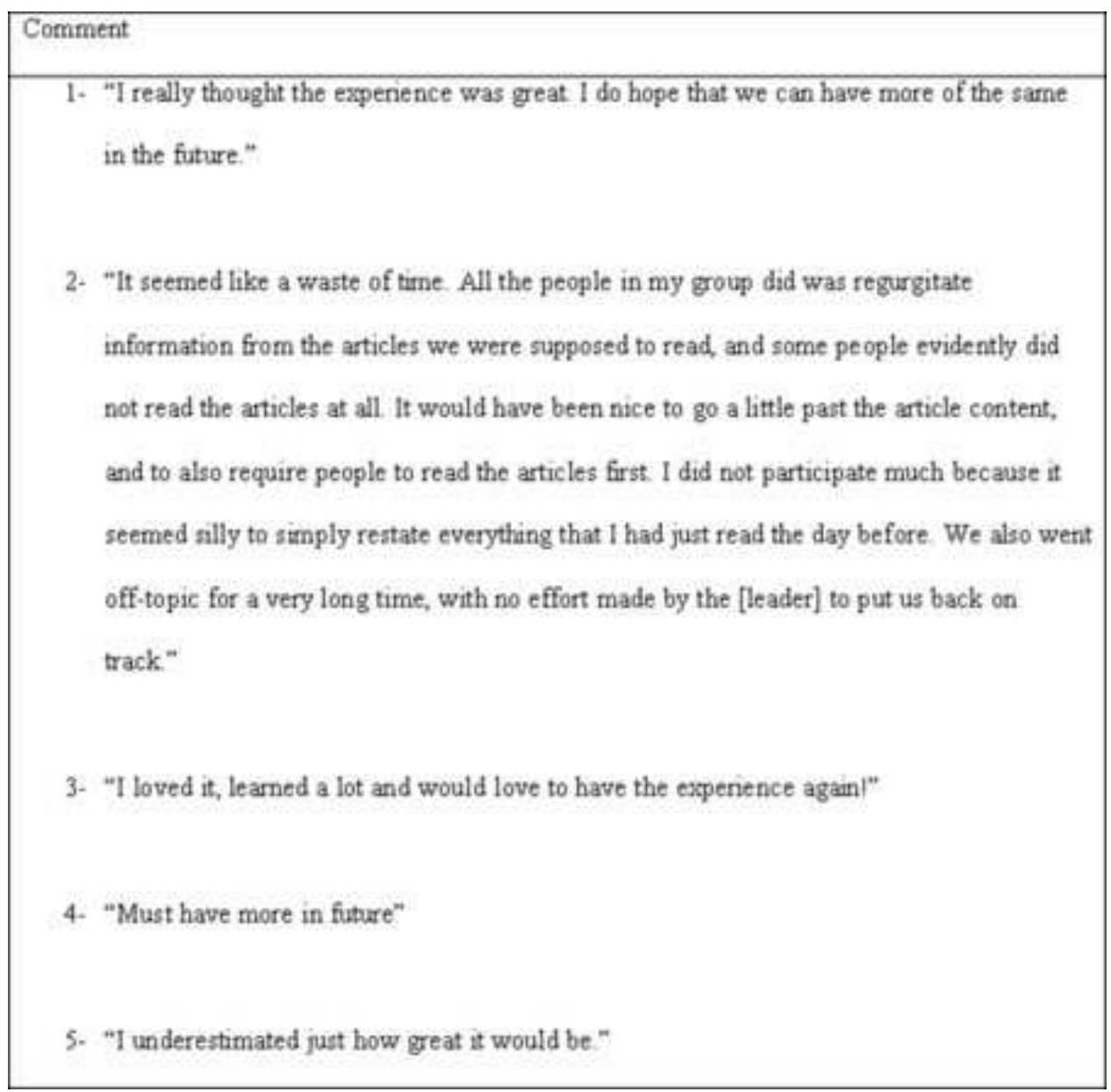

Table 2 - A sample of comments from Global Health participants in CBL

\section{Discussion}

Our low response rate makes generalizations problematic. However, some wisdom can be extracted from these data. For the objectives of this study, our results point to an innate value in CBL for teaching Global Health. Of course, it is quite possible that only those most moved by the experience were motivated to complete the questionnaire, thus biasing our results toward the valuing of CBL.

Case-based learning is innately a qualitative process. Some subjects, such as hard sciences, and even some topics in Medicine, lend themselves to definitive solutions to well defined problem scenarios. The imprecise and opinion-based nature of Global Health makes it theoretically an appropriate subject for the CBL treatment. However, its CBL's qualitative nature that also presents its challenges, particularly with respect to standardizing experiences across student groups.

According to our admittedly limited data, while the overwhelming majority of students reported valuing the $\mathrm{CBL}$ experience, responses indicated that one group suffered from poor leadership, poor participation and lack of discussion focus. Given the need to harmonize experiences of students across all groups within a given class, for CBL to be regularly incorporated, more attention needs to be placed on the training of session leaders. It is also possible that as students become more used to the format, expectations will become clearer, and experiences more similar.

It is not surprising that respondents reported such a diverse array of subjects touched upon during their discussions, as such diversity is the essence of the subject of Global Health. This finding reinforces the value of $C B L$ in accessing the innate complexity and interdisciplinary nature of a course that would 
otherwise have to rely on more direct, didactic methods of teaching. The power of CBL to leverage interand multidisciplinary approaches has been discussed before, in such arenas as Nursing and public health training $[5,6]$. However, we believe its relevance to Global Health, quite similar to public health, is particularly noteworthy. It is reassuring that most respondents preferred this format to both lectures $(73 \%)$ and unstructured small group discussion (60\%).

Our results also indicate that an integrated medical school model is worth pursuing; specifically, a format of introducing a specific topic in a traditional lecture format (preferred by $73 \%$ of respondents), engaging in $C B L$, then following-up on the same topic with an additional lecture (preferred by $53 \%$ of respondents). This wrapping approach would address all students' individual learning styles, would ensure that all students are exposed to essential core materials, and would reinforce the key lessons of the experience. However, such an expensive and time-intense strategy cannot be applied to all topics in a given class, and must be reserved for special topics that either define the discipline or convey specific learning objectives that are the most relevant to the overall course.

As observed by White in 1996 [7], "content laden lectures delivered to large enrolment classes typify science courses at most universities and many colleges." The Global Health class in which this study was set suffers from unusually large enrolment, hobbling its ability to explore nuances in the field. The goal for pedagogy at this level should be complex thinking, intellectual leadership and self-driven inquiry, none of which are served by the traditional lecture, or even small tutorial formats. One of the defining traits of $\mathrm{CBL}$ in a small group format is that students accept the responsibility for their own learning [8], an element desperately needed for advanced work in all fields of multidisciplinary health sciences.

With sustained investment in the training and retaining of session leaders, the development of relevant multifaceted cases and efforts to maintain small group sizes, CBL can be a vital and effective format for the conveyance of the complex, current and interdisciplinary aspects of Global Health theory. 


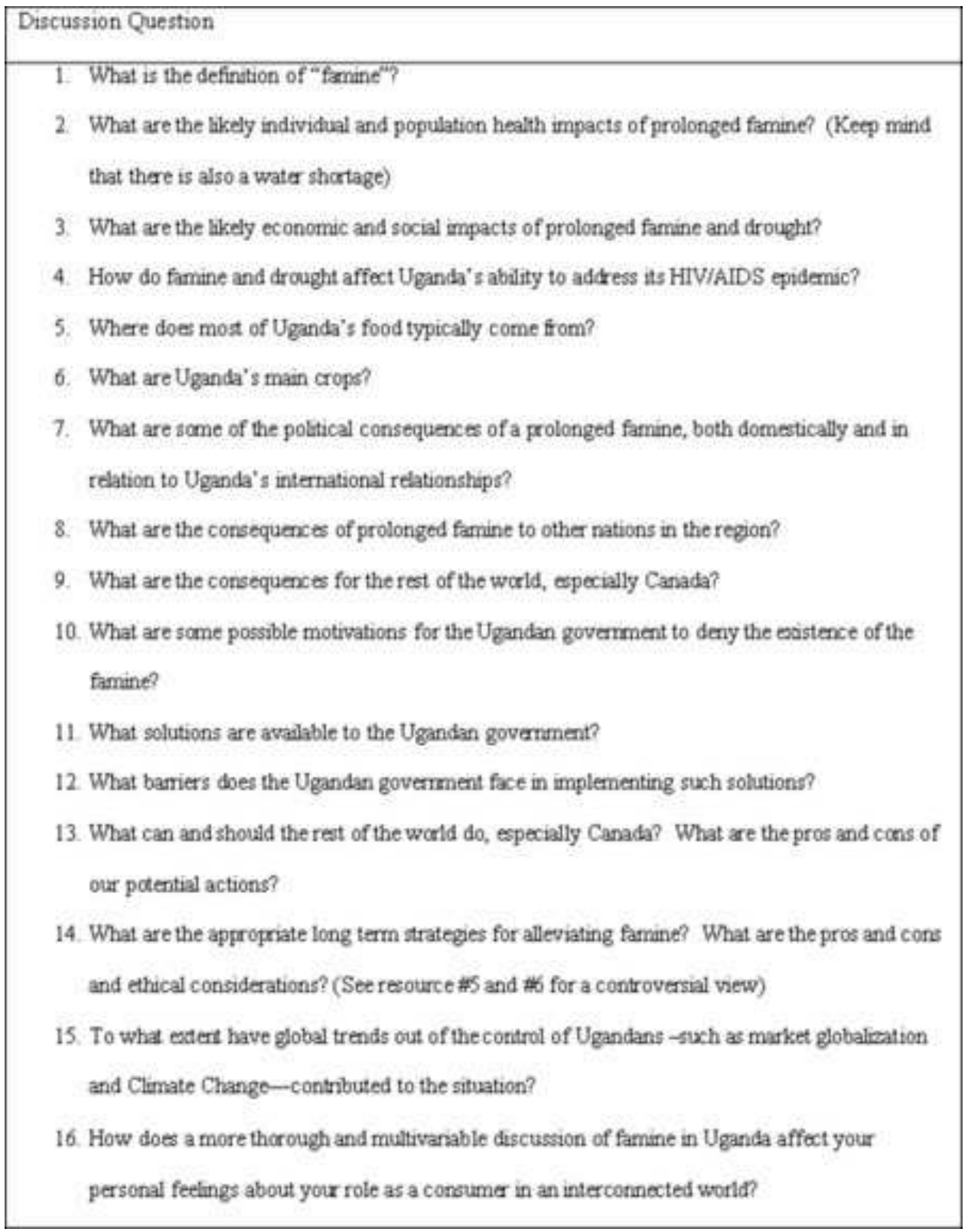

Appendix 1: Discussion questions included in case titled, "Famine in Uganda".

\section{References}

1. Neville AJ. (2009). Problem-based learning and medical education forty years on. A review of its effects on knowledge and clinical performance. Med Princ Pract. 18(1):1-9. Epub 2008 Dec 4.

2. Kardos G. (1979). Engineering Cases In The Classroom, Proceedings of the National Conference On Engineering. Available online at: http://www.civeng.carleton.ca/ECL/cclas.html

3. Williams S. (1992) Putting Case-Based Instruction Into Context: Examples From Legal and Medical Education. Journal of the Learning Sciences, 2, 367- 427.

4. Wiliams B, Duch B. (1997). Cooperative problem-based learning in an undergraduate classroom. In A.P. McNeal and C. D'Avanzo (Eds.), Student Active Science: Models of Innovation in College Science Teaching. Saunders.

5. Nango E, Tanaka Y. (2010). Problem-based learning in a multidisciplinary group enhances clinical decision making by medical students: a randomized controlled trial. J Med Dent Sci. Mar;57(1):109-18. 
6. Yamada S, Durand AM, Chen TH, Maskarinec GG. (2007). Interdisciplinary problem-based learning as a method to prepare Micronesia for public health emergencies. Pac Health Dialog. Mar;14(1):98-102.

7. White HB. (1996). Dan tries problem-based learning: A case study. In L. Richlin (Ed.), To Improve the Academy, vol. 15 (pp. 75-91). Stillwater, OK: New Forums Press and the Professional and Organizational Network in Higher Education

8. Savery JR. (2006). Overview of Problem-based Learning: Definitions and Distinctions. The Interdisciplinary Journal of Problem-based Learning. 1(1):9-20.

Generated at: Tue, 22 May 2012 22:38:45 -0500 (00002b92) - http://www.ispub.com:80/journal/theinternet-journal-of-medical-education/volume-2-number-2/a-pilot-study-for-case-based-learning-amongundergraduate-students-in-global-health.html 